\title{
Using Push Technology for Maintaining Proficiency and Promoting a Growth Mindset in a STEM Course
}

\author{
Carla van de Sande \\ Arizona State University \\ Mark Reiser \\ Arizona State University
}

Just like physical skills, cognitive skills grow rusty over time unless they are regularly used and practiced. This means that school breaks can have quite negative consequences on student learning. The Keeping in School Shape (KiSS) program is an engaging, innovative and cost-effective intervention that uses push technology to help students maintain proficiency over breaks from school, while also promoting a growth mindset. Theoretically, the KiSS program draws on the well-documented benefits of retrieval practice - the notion that recalling previously material is a very effective way of maintaining cognitive performance. The KiSS program embodies retrieval practice by sending students a multiple-choice mathematics question daily via text messaging or email. A positive mindset regarding the benefits of effort is promoted through feedback messages that encourage program resource use, such as choosing to view a hint and retry a problem instead of giving up. This paper reports on a few aspects of the implementation of the KiSS program at a large university during the summer break for students enrolled in an engineering introductory calculus course sequence.

Keywords: push technology, retrieval practice, student engagement, mathematics learning, summer slide

\section{INTRODUCTION}

Many Science, Technology, Engineering, and Mathematics (STEM) topics require proficiency in previously learned skills and concepts. Introductory STEM course sequences mimic this structure so that foundation courses feed into subsequent closely-related courses. Students finish the foundation course with skills and confidence that are critical to their success in the target course. However, this growth can erode in the time between the courses, especially if there is a prolonged gap of academic engagement (e.g., summer slide) (Cooper et al. 1996), or if the way they absorbed the information wasn't conducive to retention (e.g., stress-induced intentional forgetting) (Ramirez et al., 2017). In order to address this loss of proficiency, many faculty, departments, and institutions of higher education would like to see students engage with course content outside of class and during academic breaks. Regrettably, this is not likely to happen spontaneously, so the issue is how to reach students and prompt them, in a non-threatening way, to stay connected with the things that they have learned and need to maintain for future learning. One way of doing this is to post reminders or information in a location that students are unlikely to miss, namely on their mobile phones, through an installed app or an external source. These unsolicited notifications are 
referred to as "pushes" because, given permission from the user, they are sent to and automatically appear on a user's phone or device.

Pushes are perhaps most commonly associated with mobile apps that are installed on a smartphone, and there are numerous apps that use push technology in an effort to retain users (Huang et al., 2010). Research on pushes connected to mobile apps shows that they can be a successful means of reaching and grabbing the attention of users (Pham et al., 2016) and reminding students to access course materials on a regular basis (Kallookaran \& Robra-Bissantz, 1017). However, pushes can be employed outside of the context of mobile apps; text messages can also be conceptualized as pushes that have the added benefit of being less time-consuming and expensive to develop. Text messaging has been successfully used to push tips for literacy skills to elementary school parents (Kraft \& Monti-Nussbaum, 2017), motivational messages to middle school students (Kraft \& Dougherty, 2013), and even entire courses to high school and college students (Ioffe, 2019). Because push-based tools have such great potential to get students' attention and prompt certain behavior, they are a promising method for implementing theories of learning. In particular, push tools can be a way to engage students in retrieval practice outside of class by delivering opportunities for students to check and see if they remember a particular skill or concept (Roediger \& Butler, 2011). Then, in the context of these knowledge checks, feedback messages can serve as valuable opportunities to instill a positive mindset to meet the needs of all students (Dweck, 2007; 2008).

This paper presents an engaging, innovative and cost-effective program that uses push technology to help students maintain proficiency over breaks from school, while also promoting a growth mindset. Theoretically, the Keeping in School Shape (KiSS) program draws on the well-documented benefits of retrieval practice - the notion that recalling previously material is a very effective way of maintaining cognitive performance. The KiSS program embodies retrieval practice by sending students a multiplechoice mathematics question daily via text messaging (or email). The problems are chosen specifically to be skills that are requisite for success in the course following the break from school.

Retrieval practice delivered daily via push notifications is consistent with the growth mindset metaphor of the brain as a muscle that grows stronger with exercise (Yeager et al., 2019). Many students approach their studies convinced that intelligence is fixed, so those who have to put forth effort lack natural talent and the ability to succeed (Dweck, 2006). This failure to believe that, through effort, the brain can grow stronger negatively affects achievement (Boaler, 2013), especially for more underrepresented groups (Aronson et al., 2002; Blackwell et al., 2007). When students engage in retrieval practice by testing themselves regularly to see if they can perform a previously learned skill or concept using a program that encourages them to fix their mistakes and challenge themselves, they are essentially flexing and toning their "brain muscle" and keeping it from atrophying with disuse. The design of the KiSS program further promotes a growth mindset by including features such as hints, the option to attempt more challenging problems, and feedback messages that praise and encourage effort.

\section{METHODOLOGY}

This paper reports on select results from an implementation of the KiSS program at a large university in the Southwest over summer break for students who were planning on taking the second course in an Introductory Calculus Course sequence for engineers in the following fall semester. Collected data included participation amounts and patterns, confidence ratings, accuracy, and use of program resources. In addition, students who participated in the program provided feedback through a survey. In this paper, we report on some select aspects of participation, accuracy, and resultant use of program resources, such as accessing a hint, electing to do a more challenging problem, and viewing the solution.

\section{The KiSS Program}

For convenience and accessibility, KiSS daily review problems are pushed to students as links in text messages. Figure 1 shows a diagram of what students enrolled in the KiSS program see. Clicking on the link takes students directly to the daily question that is housed in Qualtrics, an online survey platform. Before attempting the review problem, they first use a 5-point scale (ranging from "not at all" to "Super 
Duper") to show how confident they are that they can answer it. Informal labels and emojis for the ratings are designed to make this self-assessment less threatening.

After that, as shown in Figure 2, students respond to the question by selecting one of the answer options, which opens up a sequence of possible choices that shape their daily interactive experience. Figure 3 depicts the possibilities that stem from getting the daily problem incorrect (getting a hint and trying again - which is encouraged, seeing the solution, or exiting). Students who get the daily problem correct have the option of doing a related more challenging problem (encouraged), seeing the solution, or exiting.

FIGURE 1

PROBLEMS ARE PUSHED AS LINKS IN TEXT MESSAGES

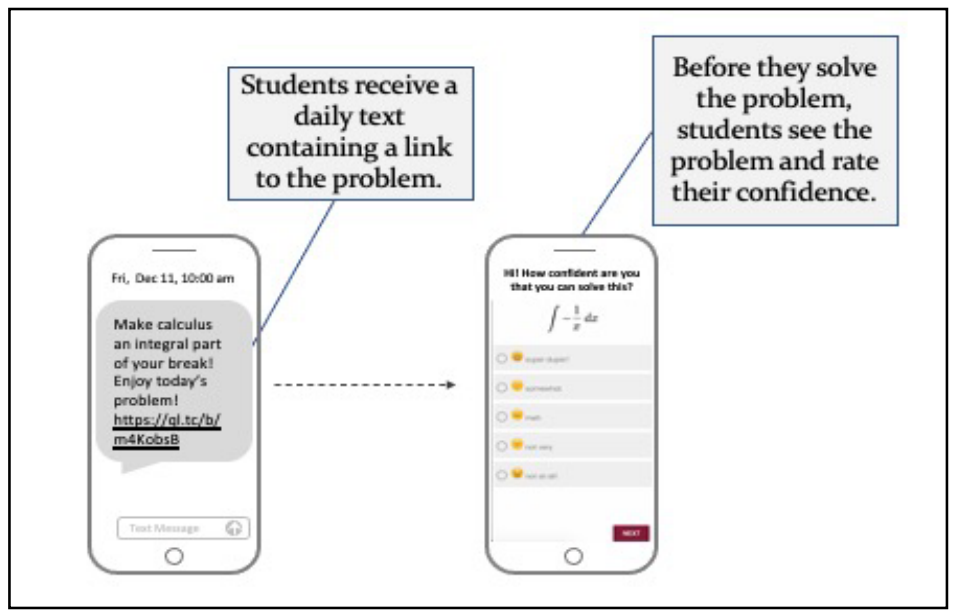

FIGURE 2

FLOWCHART SHOWING PATHS FOR STUDENT INTERACTIVE EXPERIENCE

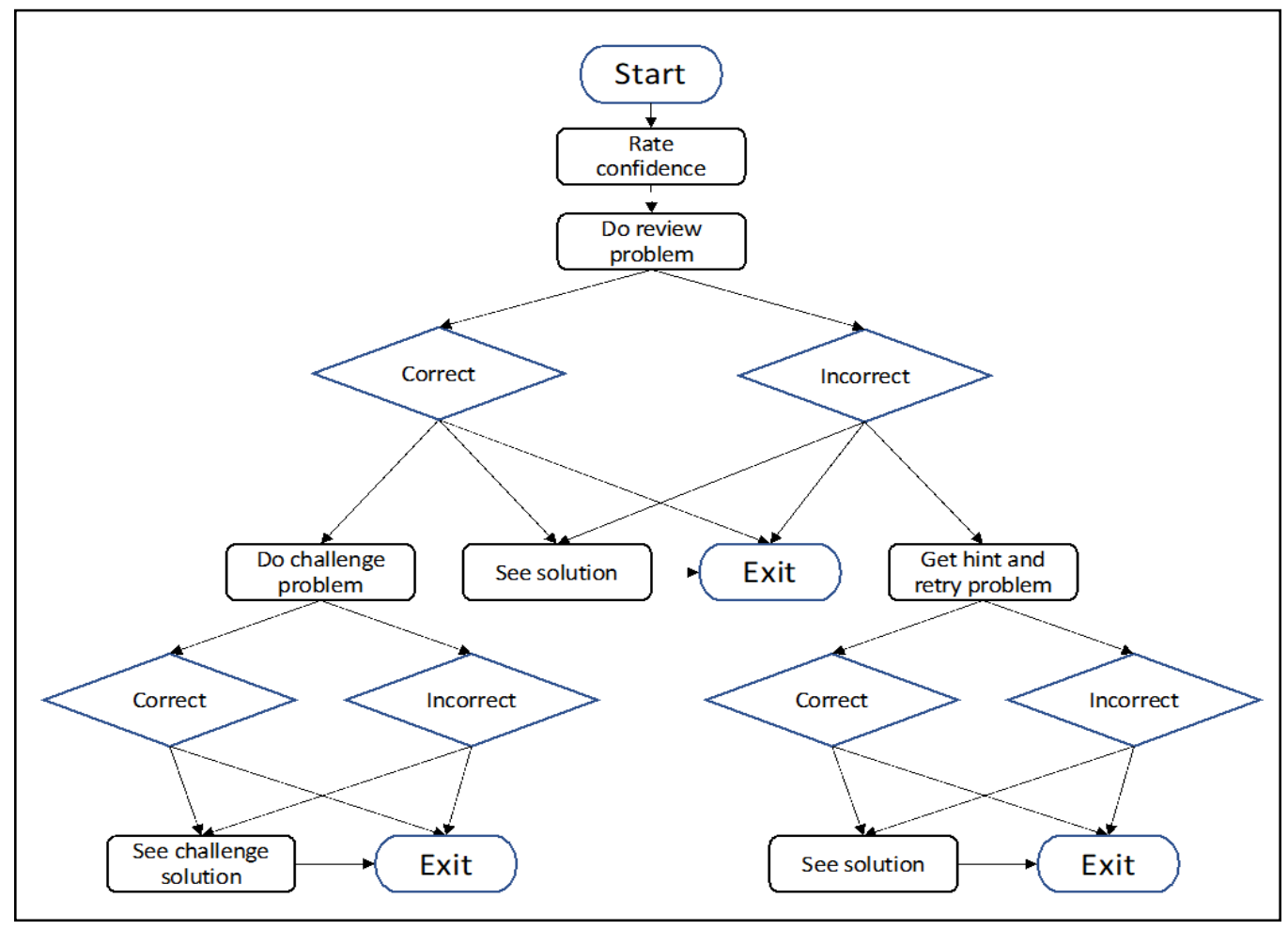




\section{FIGURE 3}

\section{OPTIONS AFTER GETTING THE DAILY PROBLEM INCORRECT}

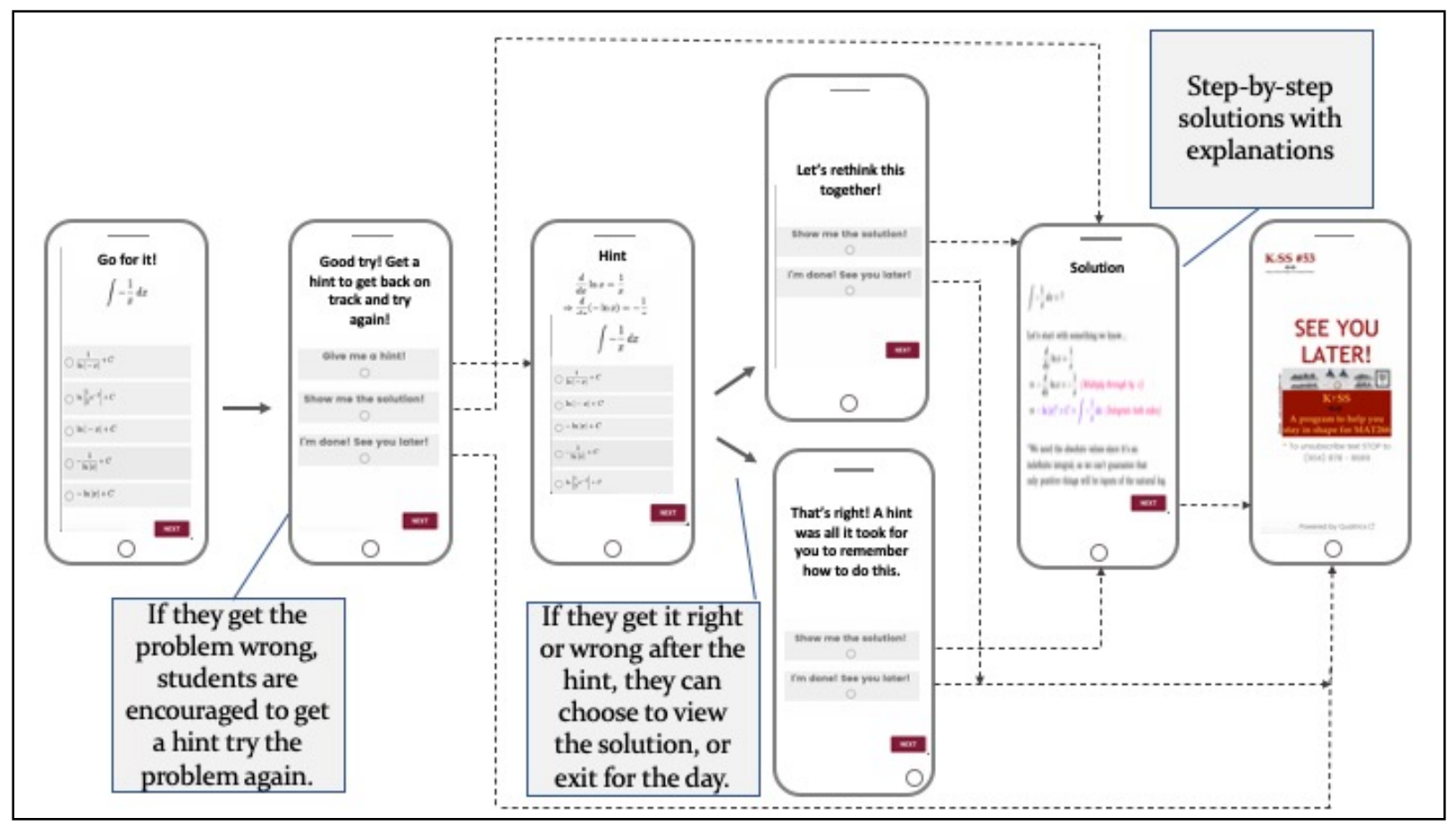

\section{Participants and Data}

Because of the pandemic, recruiting efforts were restricted to email notifications. Following the end of the spring semester, students at a major university in the Southwest who were enrolled in the second course in an Introductory Calculus Course sequence for engineers in the following fall semester were invited via email to participate in the KiSS program over the summer. Students who responded by texting a selfselected code name were enrolled in the program and received a daily (with the exception of national holidays) problem for 82 days. Each day, the following data was logged for each participant: time and duration of participation, confidence rating, answer choice, and options selected within the daily activity.

\section{RESULTS}

\section{Participation}

Because we do not know how many students saw the email invitation, we cannot calculate an exact participation rate. However, $79 \%$ of the 155 students who responded with a self-selected code name completed at least one problem in the program. Figure 4 shows the number of students who participated each day. The shaded bands represent weeks, with Saturdays and Sundays at the right of each band. As seen, participation was highest during the first week of the program and then decreased slightly over time. Perhaps not surprisingly, participation on weekends, especially on Saturdays, was generally lower than on other days of the week.

On average, students completed $41 \%$ of the total problems, with a median participation of $32 \%$. Figure 5 shows the number of students who different amounts of the total problems. As can be seen, completion of less than $15 \%$ and more than $76 \%$ of the problems were the most common amounts of participation. In essence, students were either avid participants who answered many, if not all, of the problems, or tepid participants who only tried a few of the problems. 


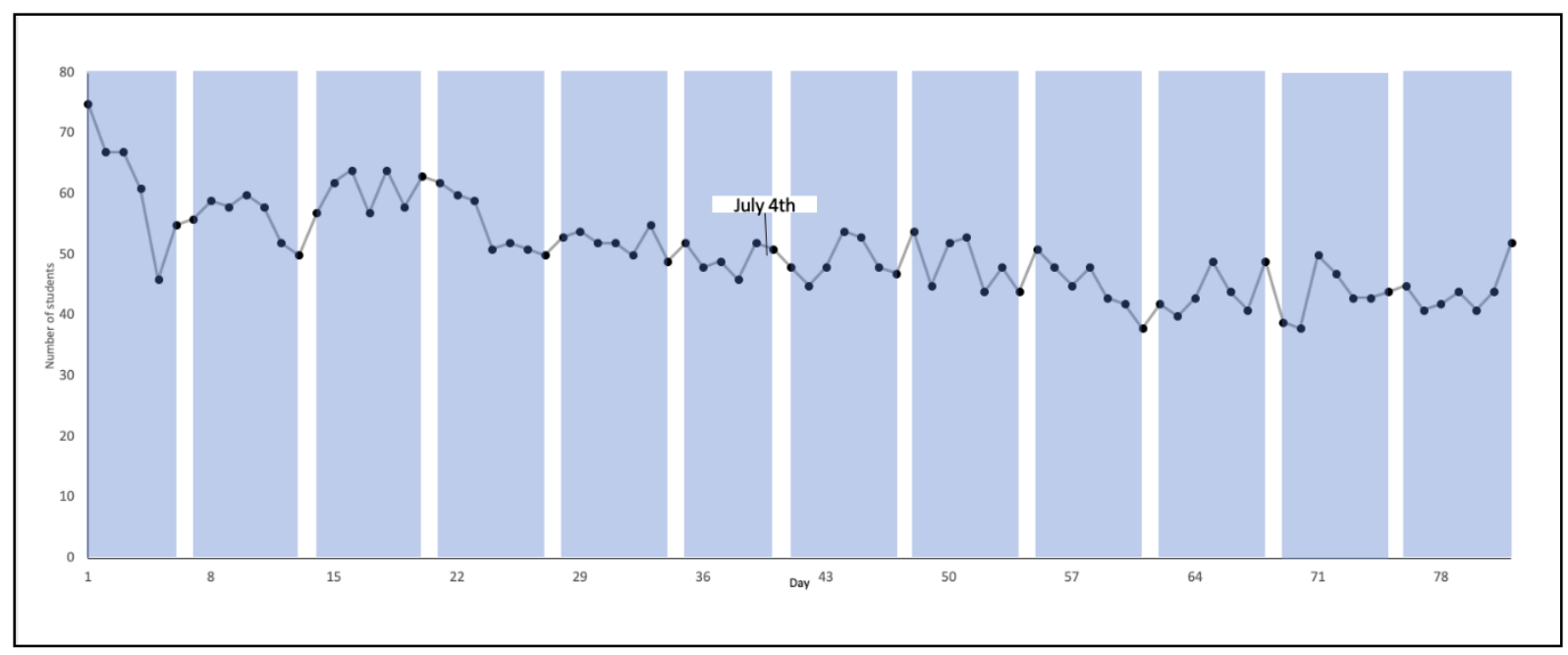

\section{FIGURE 5 \\ PERCENTAGE OF PROBLEMS COMPLETED BY NUMBER OF STUDENTS}

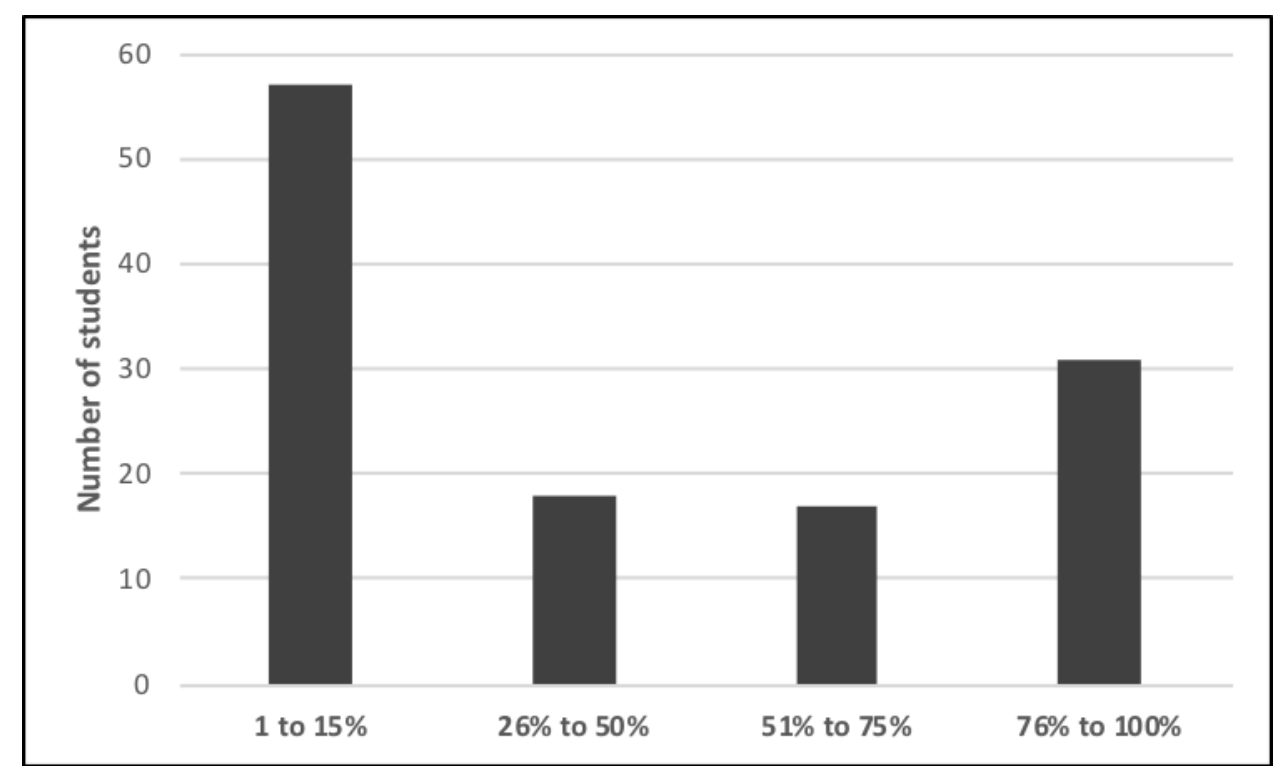

\section{Accuracy and Resource Use}

Figure 6 shows the resources used by students after solving the daily problem. About half of the time, when students got the problem correct, they elected to do a related more challenging problem. In addition, many of the students who did not opt for the challenge viewed the solution which often contained references to where the daily problem fit into the second course curriculum. However, approximately $25 \%$ of the time, students exited the program for the day after getting the daily problem correct. The majority of students who got the daily problem incorrect chose to view a hint and retry the problem. Almost all of those who did not choose this option, chose to view the solution instead of simply exiting for the day. Thus, getting the daily review problem incorrect prompted students to engage further with program, either by attempting the problem a second time or by viewing the solution. 
FIGURE 6

PERCENTAGE OF STUDENTS AND RESOURCE OPTIONS

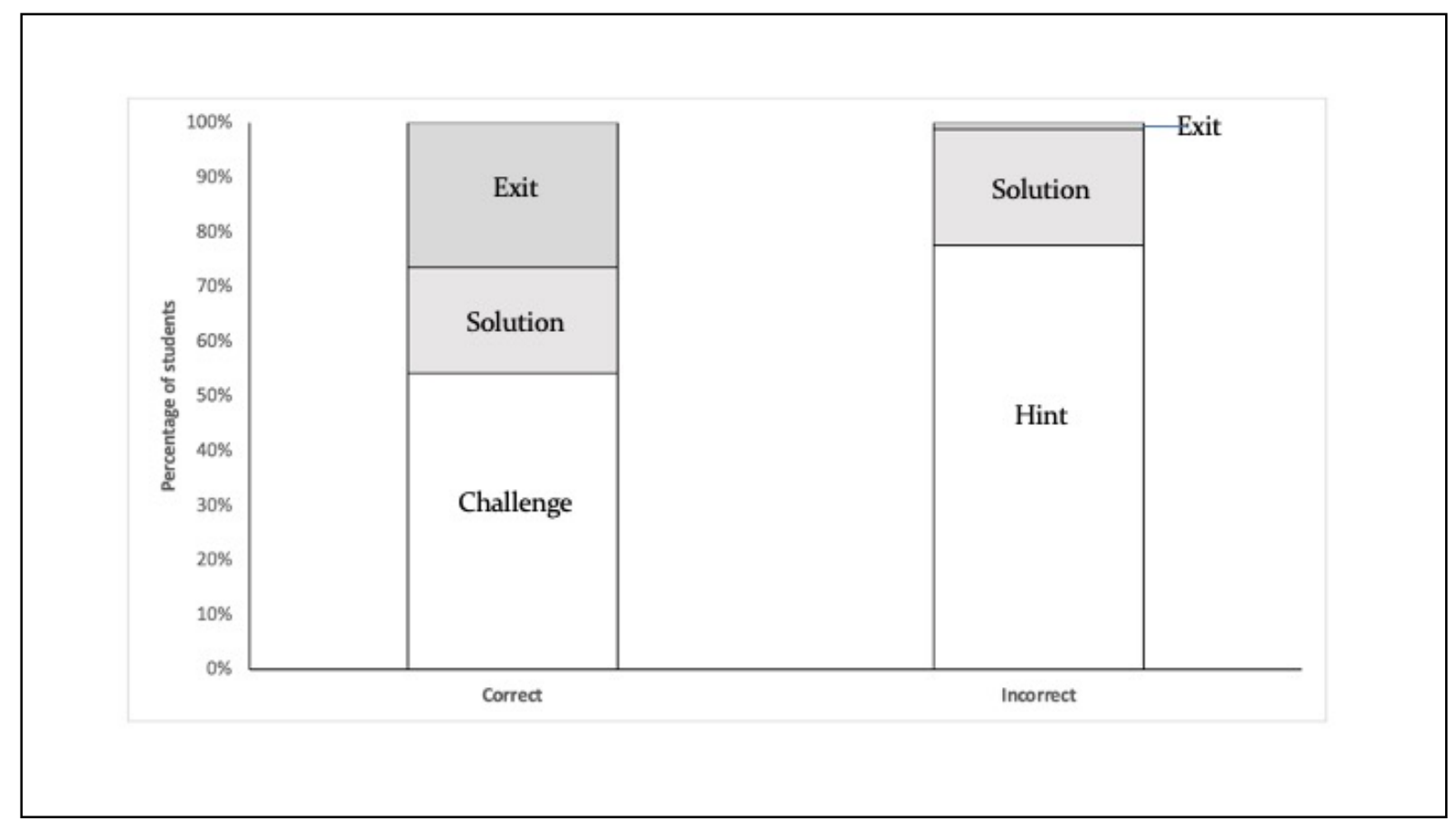

\section{CONCLUSIONS}

This paper discusses only a very few facets of how push technology can be used to engage students in maintaining proficiency over breaks from formal instruction. First, given that students would otherwise not be testing themselves daily, the amount of participation is quite promising and could presumably be increased with more sophisticated and targeted marketing efforts. Also, the KiSS program appeared to be successful at supporting a growth mindset. Many students challenged themselves, instead of just playing it safe after getting the initial problem of the day correct, and students who did not get the daily problem correct made use of the hints and solutions, instead of just giving up. Since we did not measure mindset at the onset of the program, we cannot say which students already had growth mindsets. However, student activity was consistent with the prompts in the program favoring challenges and hints over alternative options. Since this implementation, the KiSS program has been expanded substantially to include many more features, such as hints for challenge problems, days on which additional similar problems are available, and weekly trivia days on which students can answer a mathematics trivia question in addition to, or instead of, the daily problem. Clearly, more research is needed to see how students engage with these features and to explore the ways in which the KiSS Program can shift and strengthen students' mindsets so that they recognize how putting forth effort can improve their ability to succeed in calculus.

While push-based tools are an efficient and effective way of connecting with students, it is not known how to design them to best meet the needs of all students. Reaching students, especially those that are vulnerable, and helping them feel connected to their instructors and to their studies in a normal and predictable fashion is especially critical in light of unexpected disruptions, such as the recent pandemic, when students are overcome with feelings of alienation, uncertainty, and anxiety (Dziech, 2020). Therefore, this line of research on the use of push technology to deliver regular review opportunities outside of class, while simultaneously framing a positive mindset, is particularly timely and warrants further attention and exploration. 


\section{REFERENCES}

Aronson, J., Fried, C.B., \& Good, C. (2002) Reducing the effects of stereotype threat on African American college students by shaping theories of intelligence. Journal of Experimental Social Psychology, 38, 113-125.

Blackwell, L.S., Trzesniewski, K.H., \& Dweck, C.S. (2007) Implicit theories of intelligence predict achievement across an adolescent transition: A longitudinal study and an intervention. Child Development, 78(1), 246-263.

Boaler, J. (2013). Ability and mathematics: The mindset revolution that is reshaping education. FORUM, $55(1), 143-152$.

Cooper, H., Nye, B., Charlton, K., Lindsay, J., \& Greathouse, S. (1996). The effects of summer vacation on achievement test scores: A narrative and meta-analytic review. Review of Educational Research, 66(3), 227-268.

Dweck, C. (2006). Mindset: The New Psychology of Success. New York, NY: Random House.

Dweck, C. (2007). Is math a gift? Beliefs that put females at risk. In S.C. Ceci \& W.M. Williams (Eds.), Why Aren't More Women in Science? Top Researchers Debate the Evidence (pp. 47-55). Washington, DC: American Psychological Association

Dweck, C. (2008). Mindsets and Math/Science Achievement. New York, NY: Carnegie Corp. of New York-Institute for Advanced Study Commission on Mathematics and Science Education.

Dziech, B.W. (2020, April 9). Students are among the most severe and overlooked victims of the pandemic. Inside Higher Ed. Retrieved from https://www.insidehighered.com/print/views/2020/04/09/students-are-among-most-severe-andoverlooked-victims-pandemic-opinion

Huang, K.H., Jun, G., \& Kuroda, D.T. (2010, August 23). Notification system for increasing user engagement. US Patent App. 12/861,680.

Ioffe, M. (2019, September 18). Learning Solutions: Artist sees the future of global eLearning - in text messages. Learning Solutions Magazine. Retrieved from https://learningsolutionsmag.com/articles/arist-sees-the-future-of-global-elearning-in-textmessages

Kallookaran, M., \& Robra-Bissantz, S. (2017). Reaching beyond the classroom through the use of push notificaitons. In Proceedings of the $50^{\text {th }}$ Hawaii International Conference on System Sciences (pp. 144-153).

Kraft, M.A., \& Dougherty, S.M. (2013). The effect of teacher-family communication on student engagement: Evidence from a randomized field experiment. Journal of Research on Educational Effectiveness, 6(3), 199-222.

Kraft, M.A., \& Monti-Nussbaum, M. (2017). Can schools enable parents to prevent summer learning loss? A text messaging field experiment to promote literacy skills. The ANNALS of the American Academy of Political and Social Science, 674(1), 85-112.

Pham, X-L., Hwang, W-Y., Nguyen, T-H., \& Chen, G-D. (2016). Effects of push notifications on learner engagement in a mobile learning app. IEEE $16^{\text {th }}$ International Conference on Advanced Learning Technologies, pp. 90-94.

Ramirez, G., McDonough, I.M., \& Jin, L. (2017). Classroom stress promotes motivated forgetting of mathematics knowledge. Journal of Educational Psychology, 109, 812-825.

Roediger, H.L., III, \& Butler, A.C. (2011). The critical role of retrieval practice in long-term retention. Trends in Cognitive Science, 15(1), 20-27.

Yeager, D.S., Hanselman, P., Walton, G.M., Murray, J.S., Crosnoe, R., Muller, C., . . Dweck, C.S. (2019). A national experiment reveals where a growth mindset improves achievement. Nature, $573,364-369$. 